\title{
COMPOSTING OF STARCH-BASED BIOPLASTIC BAGS: SMALL SCALE TEST OF DEGRADATION AND SIZE REDUCTION TREND
}

\author{
Maria Cristina Lavagnolo ${ }^{1}$, Federica Ruggero ${ }^{2, *}$, Alberto Pivato ${ }^{1}$, Carlo Boaretti ${ }^{3}$ and \\ Alessandro Chiumenti ${ }^{4}$ \\ ' DICEA, Department of Civil, Architectural and Environmental Engineering, University of Padova, via Marzolo 9, 35131 Padova, Italy \\ 2 DICEA, Department of Civil and Environmental Engineering, University of Firenze, via di S. Marta 3, 50139 Firenze, Italy \\ ${ }^{3}$ DII, Department of Industrial Engineering, University of Padova, via Gradenigo 6/a, 35131 Padova, Italy \\ ${ }^{4}$ Department of Agricultural, Food, Animal and Environmental Sciences (DI4A), University of Udine, via delle Scienze 206, 33100 Udine, \\ Italy
}

Article Info:

Received:

11 May 2020

Revised:

6 August 2020

Accepted:

24 August 2020

Available online:

30 September 2020

Keywords:

Bioplastics

Microplastics

Composting

Biodegradation

Fragmentation

\section{ABSTRACT}

In Italy, the majority of bioplastic bags used in food waste collection is made of starch-based biopolymer. The compostability of this material in a full-scale plant remains to be demonstrated, largely due to the fact that bioplastic bags are screened and removed together with conventional plastic bags during pre-treatment steps. The present research was performed on a small scale to study the degradation of starch-based bioplastics during composting. Evolution of the physical and chemical parameters of the material was evaluated by means of Fourier Transform Infrared (FTIR), experimental mass loss and granulometric trend. The results obtained suggested that fragmentation (physical size reduction of the material) occurred mainly during the thermophilic phase, while biodegradation (breakdown by microorganisms of an organic chemical into simpler, innocuous compounds) occurred during the curing phase. Based on the monitored parameters (TS, VS, pH, C/N and $\mathrm{RI}_{4}$ ), the composting process of the waste matrix ended after 55 days, but the degradation of bioplastics failed to achieve the regulatory standards for assessment of compostability $(\leq 10 \%$ sized $>2 \mathrm{~mm})$. Experimental data revealed a linear trend for the fragmentation process and a duration of 100 days would be required to meet regulatory requirements.

\section{INTRODUCTION}

The management of plastics continues to present a series of challenges worldwide (Hahladakis et al., 2018). The magnitude of the problem is highlighted by the finding published by ISPRA (ISPRA, 2019) that plastic waste represents $30 \%$ of total waste generated yearly. One of the main waste streams is constituted by plastic bags, a serious environmental concern worldwide due to the enormous quantities produced and low recovery rate. However, production and use of plastic bags is achievable by political means: by banning plastics or taxing the production and use of plastic bags whilst promoting alternatives such as paper or bioplastic bags (e.g.: EU, 2018; Italian Legislative Decree 123/20179) (Byun and Kim, 2013).

Bioplastics, characterised by production from renewable sources (bio-based) and biodegradability (biodegradable), represent an effective and sustainable alternative to traditional plastics (Yates and Barlow, 2013).

Indeed, bio-based plastics are deemed environmen- tally-friendly materials (Karana, 2012), being produced by means of a cleaner production cycle than petrol-based plastics. Moreover, bioplastics may potentially be suitable for reintroduction into the soil following decomposition (in the case of biodegradable materials)

However, the biodegradability of bioplastics is an important issue as products, either accidentally or on purpose, frequently end their life cycle in the environment (soil or water) (Shruti and Kutralam-Muniasamy, 2019). Indeed, the term biodegradability relates in particular to the environmental context in which bioplastics are disposed, with some commonly used bioplastics being biodegradable through composting, in accordance with EN 13432 (EN $13432,2000)$. Importantly, the characteristics required to allow the treatment of bioplastics by means of composting are as follows: biodegradation relates to the breakdown of an organic chemical compound by microorganisms, whilst compostability to the suitability of a packaging material to undergo biodegradation in a composting process. To attest this suitability, following assessment of a fragment of the 
material, no more than $10 \%$ of the initial material should fail to pass a $2 \mathrm{~mm}$ sieve at the end of the process; thus, a $2 \mathrm{~mm}$ dimension is the threshold below which residues are considered assimilable compost in accordance with current regulation.

Biological processes in composting are carried out by a consortium of various microorganisms (bacteria, actinomycetes, fungi, yeasts, etc.) and determine the degradation of organic matter accompanied by release of thermal energy and consequent temperature increase, in many cases exceeding $55^{\circ} \mathrm{C}$. Experiments conducted on the degradation of bioplastics through composting have yielded at times divergent results. (Emadian et al., 2017), (Mohee et al., 2008). Balaguer et al, 2016, (Balaguer et al., 2016) observed an effective action in terms of degradation of bioplastics, while others reported only $26.9 \%$ of degradation due to the presence of lower temperatures (Mohee et al., 2008).

When subjected to unfavourable composting conditions (mainly low temperatures and insufficient composting time), bioplastics may not disappear completely but merely break down into microscopic pieces. Therefore, the difficulty of using the compost on cultivated fields may impact negatively on market demand for the product.

Currently, the majority of industrial composting plants are not equipped to receive bioplastic bags, as these are selected by pre-treatment and removed from the composting line together with conventional plastic bags. As a consequence, numerous aspects of bioplastic composting remain to be ascertained: how initial size affects the degradation process; whether the time frame applied in food waste composing is sufficient to comply with the standards for bioplastic size reduction; and the fate of microplastics generated once treatment has been completed.

Starch-based bioplastic bags are currently the most widely used carrier bags in Italy. Use of these bags is undoubtedly destined to increase further in the future, particularly in view of the strict limitation of single-use plastics imposed by the European Circular Economy package (Package., 2018) (Hahladakis and lacovidou, 2018). The biodegradation of starch-based film bioplastics under composting has been studied by previous authors in different conditions, generally at lab scale and with constant temperature and humidity (Ruggero et al., 2019). A degradation ranging from 30 to $45 \%$ was found in mesophilic conditions (Mohee et al., 2008) (Accinelli et al., 2012) (Massardier-Nageotte et al., 2006), while if composting is carried out with a temperature not lower than $58^{\circ} \mathrm{C}$ for a period longer than 45 days, the degradation reaches $90 \%$ (lovino et al., 2008), (Javierre et al., 2015) (Gómez and Michel, 2013).

The present study, performed on a small scale, was aimed at providing an additional insight into the degradation of starch-based bioplastics during the composting process. Important parameters monitored during the process included the concentration, size and mass of bioplastics. The chemical composition and structure of the material were investigated by means of Fourier Transform Infrared (FTIR).

\section{MATERIALS AND METHODOLOGIES}

\subsection{Experimental set-up}

The experimental tests were performed in small-scale pyramidal composting heaps of $30 \mathrm{~kg}$ of waste, organized in two replicates referred to as Line 1 and Line 2, each comprising three heaps. One blank containing only the organic fraction of waste (OF) and two heaps with a mix of OF and the tested bioplastics manually cut into two different sizes were set up (Figure 1).

Waste composition for heaps was generated considering the need to simulate the waste matrix of food and green waste generally entering composting plants; it was selected on the basis of indications provided by ARPAV (Regional Environmental Protection Agency of Veneto) (Veneto Region, 2015): kitchen waste (53\% on wet basis), wood chips (33\%), grass (3\%), with an inoculum of compost $(11 \%)$ to facilitate start-up of the process. Heaps were placed in a climatic chamber under controlled temperature and humidity, which was monitored daily. Tests were carried out to evaluate granulometry, concentration, and physicochemical features of bioplastics: sampling was performed on $10^{\text {th }}, 25^{\text {th }}, 40^{\text {th }}$ and $55^{\text {th }}$ days with an aim to clarifying evolution during the composting process.

\subsection{Tested material}

Tested material consisted of starch-based bioplastic carrier bags; the composition of this material, commercially available in Italian supermarket, is $30 \%$ of starch and $70 \%$ of polybutylene adipate terephthalate (PBAT), a biodegradable not biobased polyester. The thickness of the material

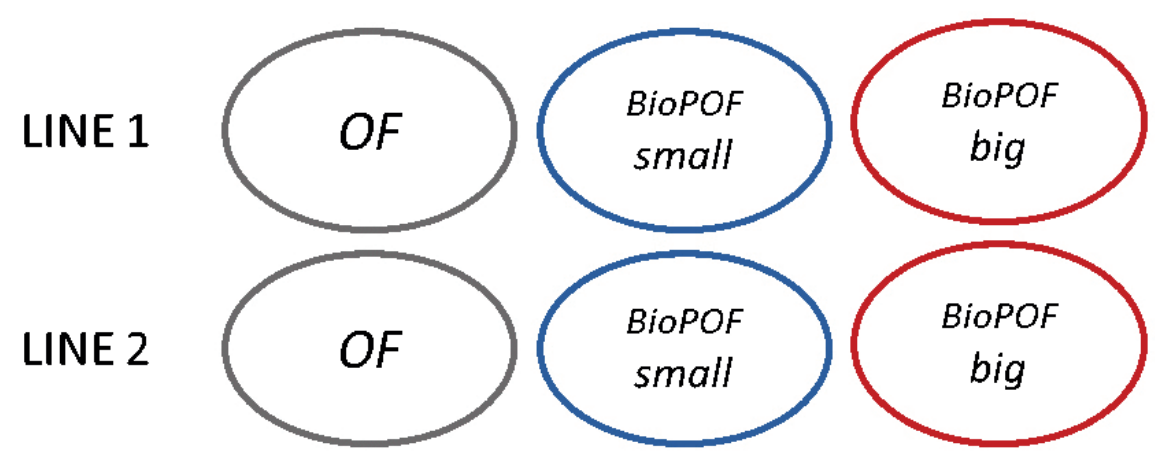

FIGURE 1: Experimental set-up of the composting test. 
was $0.5 \mathrm{~mm}$. The initial concentration of the tested material in the waste matrix was of $7 \mathrm{~g}$ bioplastics for each kilogram of mixture. Parameters used in identifying the latter were based on: (i) the current quantity of compostable bioplastics produced in Italy (Assobioplastiche, 2018); (ii) the increasing trend of $30 \%$ foreseen over the next five years (Bioplastics European, 2019); (iii) the amount of waste to composting (ISPRA, 2017); (iv) variables identified in the use of biobags by Italian families, including number of householders, seasonal variations in collection timing, and type of collection (Peelman et al., 2013).

As shredding tools adopted in composting plants determine a final size ranging from a maximum of $70-80 \mathrm{~mm}$ to a minimum of $20-10 \mathrm{~mm}$, the initial size of bioplastic pieces represented a test variable and bags were shredded into two size ranges: from 50 to $70 \mathrm{~mm}$, and from 20 to $30 \mathrm{~mm}$, referred to as BioPOF big and BioPOF small, respectively.

\subsection{Composting monitoring parameters}

Typical parameters of composting process were monitored throughout the test. First, the heaps were weighted with a balance (gram precision) to evaluate mass trend during the process and to obtain the BioPOF mass for each heap. Total and volatile solids (TS and VS) were measured in accordance with the standard method IRSA-CNR Q $64 / 84$ vol. 2 n. 2 . A Benjamin by Vittadini - Suprema 600 oven and a Gefran 1001 muffle were used to analyse TS and VS, respectively.

Temperature was monitored three times a day using an Endress + Hauser - RSG40 probe at the centre and bottom of the heaps to obtain a daily average value for each heap.

Although in the presence of a negligible inorganic fraction, Total Carbon was measured in accordance with the UNI EN 13137 standard using a Shimadzu - TOC-V CSN Total Organic Carbon Analyzer combined with an SSM 5000 Solid Sample Module.

Total Nitrogen (TKN) was measured in accordance with IRSA-CNR Q 64/85 vol. 3 n. 6 mod. standard using the following equipment for the three phases of analysis: Velp Scientifica - DKL Heating Digester, Velp Scientifica - UDK 127 Distillation Unit and Crison - TitroMatic.

The IRSA-CNR Q 64/86 vol. 3 n. 8a standard was used to measure nitric nitrogen for transfer of the solid sample to the liquid phase, and IRSA-CNR 29/2003 vol. 2 n. 4040 A1 standard to measure analytical parameters of the liquid by means of UV analysis using Shimadzu - UV - 1601 UVVisible Spectrophotometer. The monitoring parameter $\mathrm{C} / \mathrm{N}$ was subsequently calculated.

Measurement of $\mathrm{pH}$ following transfer to the liquid phase was conducted on the liquid sample as established in IRSA-CNR 29/2003 vol. 1 n. 2060 using a Crison - TitroMatic.

To conclude, static and dynamic respirometric indexes $\mathrm{RI}_{4}$, were measured by means of the SAPROMAT method (Federal Compost Quality Assurance Organization) using a Sapromat model E.

Table 1 reports parameters for the initial waste matrix, in comparison with values required by standard EN 14045 (EN 14045, 2003).
TABLE 1: Chemical characteristics of the initial compostable feedstock.

\begin{tabular}{l|c|c} 
Parameters & $\begin{array}{c}\text { Initial compostable } \\
\text { matrix }\end{array}$ & $\begin{array}{c}\text { Reference values (EN } \\
\text { 14045) }\end{array}$ \\
\hline Moisture (\%) & 54 & $>40-50$ \\
\hdashline $\mathrm{VS}(\%)$ & 91 & $>50$ \\
\hdashline $\mathrm{C} / \mathrm{N}$ & 34 & $20-35$ \\
\hline $\mathrm{pH}$ & 6 & $>5$ \\
\hline $\mathrm{RI}_{4}\left(\mathrm{mgO}_{2} / \mathrm{g} \mathrm{TS}\right)$ & 50 & - \\
\hline
\end{tabular}

\subsection{Evaluation of bioplastics fragmentation and degradation in composting}

\subsubsection{Granulometry of bioplastics}

To evaluate the fragmentation of bioplastics (physical size reduction), sieving analysis as established in EN 13432 was considered as a reference. However, since the focus of the study was to investigate the fragmentation of bioplastics both throughout and on completion of the process, sieving analysis was carried out on the $10^{\text {th }}, 25^{\text {th }}, 40^{\text {th }}$ and $55^{\text {th }}$ days of the test. For each analysis, $500 \mathrm{~g}$ of composted BioPOF big and BioPOF small wastes were sieved through six meshes, in accordance with ASTM international classification: $3 / 4,3 / 8,5 / 16,3.5,8$, and 14 , corresponding to $20 \mathrm{~mm}, 10 \mathrm{~mm}, 8 \mathrm{~mm}, 5.60 \mathrm{~mm}, 2.38 \mathrm{~mm}, 1.40 \mathrm{~mm}$. The fractions of bioplastics passing through sieve 3.5 were considered micro-pieces.

After sieving, each granulometric fraction was visually screened to recover bioplastic fragments; this procedure for fragments recovery is suggested also in the main standards for bioplastics compostability (e.g. EN 13432). However, to improve the identification of the smallest particles, down to the size of $1 \mathrm{~mm}$, the procedure was enhanced by a magnifying glass, diameter $50 \mathrm{~mm}$ and magnification $5 \mathrm{x}$, and carried out for the same sample at least by three operators to reduce the subjectivity of the naked eye.

These fragments were weighted ( $\mathrm{g}$ BioP) and used to calculate the concentration of bioplastics in the $500 \mathrm{~g} \mathrm{Bi}-$ oPOF sample.

The granulometric curve, describing the percentage of bioplastics retained in mass for each heap at any sampling time, was drawn.

Finally, bioplastics mass measured in each granulometric fraction was exploited to build a curve showing an average trend of granulometric size reduction during composting, applying Equation 1.

$(\text { Average BioP size })_{j}=\sum_{i}\left((\text { BioP \% mass })_{i}(\text { BioP size })_{i}\right)_{j}$

Where $\mathrm{j}$ is the sampling day, from 0 to 55 , and $\mathrm{i}$ are the granulometric fractions $(20 \mathrm{~mm}, 10 \mathrm{~mm}, 8 \mathrm{~mm}, 5.60 \mathrm{~mm}$, $2.38 \mathrm{~mm}, 1.40 \mathrm{~mm}$ ); is identical with the mesh size of the sieve and is obtained with Equation 2.

$(\text { BioP } \% \text { mass })_{i}=100 * \frac{(g \text { BioP })_{i}}{\sum_{i}(g \text { BioP })_{i}}$

\subsubsection{Bioplastics mass}

An important information to be obtained from the analysis is related to the decrease of total bioplastic amount (g) in the waste matrix during composting. To extrapolate 
the total mass of bioplastics (total BioP mass) in the heap at each sampling time, the bioplastic concentration previously obtained in the $500 \mathrm{~g}$ sampled from each heap was used. To obtain this unknown value, concentration was multiplied by total mass of the heap (BioPOF mass):

$\left(\frac{g \text { BioP }}{g \text { BioPOF }}\right) *$ BioPOF mass $(g)=$ total BioP mass $(g)$

However, two features in particular impacted on the experimental mass calculated as per Equation 1, namely increased moisture content in bioplastics, ranging from 5 to $9 \%$, empirically evaluated by means of total solids analysis, and percentage of mass increase caused by waste adhering to the surface (dirt). The latter variable was defined on the basis of experimental data yielded by calculating the difference in mass before and after the cleaning of bioplastic pieces. The cleaning operation was carried out on samples of five pieces gathered from different size categories, for different days of analysis and from different heaps. These samples were weighted, cleaned using spatulas, hard brushes and tweezers to remove other adhering wastes and once again weighted. The percentage of dirt thus obtained was subtracted from total mass.

\subsubsection{Degradation of bioplastics assessed by FTIR analysis}

Fourier Transform Infrared (FTIR) spectra were obtained in total reflectance mode (ATR) with Thermo Scientific $^{\text {TM }}$ Nicolet $^{\text {TM }}$ iS $^{\text {TM }} 10$ FTIR Spectrometer with $2 \mathrm{~cm}^{-1}$ spectral resolution, coupled with OMNIC software. Fragments of bioplastics were recovered during the composting process for the analysis; these had been previously cleaned and tooth-brushed in order to remove all waste residues from their surface. The investigated wavenumber range was $4000-600 \mathrm{~cm}^{-1}$. The spectra were acquired in absorbance. The variation observed in peaks intensity and wavenumbers provides qualitative information on chemical change to the polymeric structure and the degradation process of materials.

FTIR analysis was also applied at the beginning of the research to different brands of bioplastic carrier bags present on the Italian market, to define each spectrum. The re- sults confirmed that, despite the different brands, composition of the tested bags was identical, being all starch-based and made by the same company.

\subsubsection{Visual analysis}

In accordance with EN 14045 (EN 14045, 2003), visual assessment criteria distribution of particle size of remaining bioplastic particles and signs of microbial colonisation of the material. Ten bioplastic particles were selected to provide an overview of all visible degradation phenomena: consistency and thickness of the material, discolouring, erosion of the material (holes, tunnels, etc.) and ease of detection. Results of each assessment relevant for the test were documented in writing and by photographs.

Furthermore, evolution of the aspect of bioplastics may define the turning point after which pieces of the tested material became assimilable to compost for size, colour, smell and features.

\section{RESULTS AND DISCUSSION}

\subsection{Evolution of composting parameters}

As expected, two main phases were identified during the composting process: a thermophilic, or high rate phase, which ended within ten days, and a mesophilic curing phase, lasting forty-five days.

Process temperatures, having a similar trend in the heaps of the two lines, were in the proximity of $60^{\circ} \mathrm{C}$ over the first ten days (thermophilic phase). After this period, the heaps presented a progressive reduction of temperature to $30{ }^{\circ} \mathrm{C}$, reaching ambient temperature in the final stage of the process.

A significant indicator of process evolution was mass variation of the heaps: mass trend and total solids content are reported in Figure 2. Mass decrease displayed the highest intensity during the thermophilic phase, reaching $60 \%$ of initial mass (40\% loss) and 30\% (70\% loss) at the end of the process. Although mass loss may vary depending on the feedstock and evolution of the composting process, this result is comparable with trends reported in literature
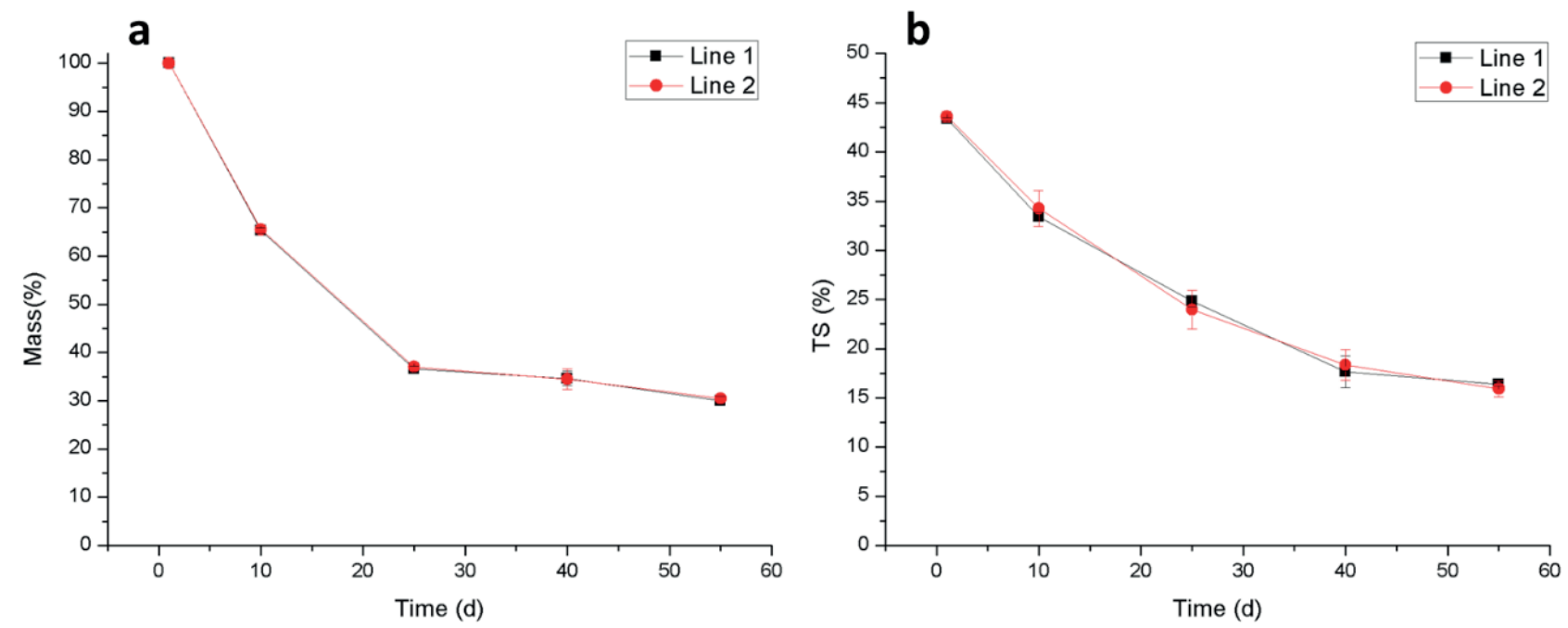

FIGURE 2: Decrease in mass (a) and total solids (b). recorded in the tests. 
(Tiquia et al., 2002).

Final values obtained for composting parameters met the requirements of EN 14045 and Italian limits for compost quality (Annex $1 \mathrm{C}$ of Law 748/84 modified by Ministerial Decree dated 27/03/98). Moisture was below $40 \%$, $\mathrm{pH}$ was in the range of 7.6-7.7, and $\mathrm{C} / \mathrm{N}$ in the range between 12 and 13 (Table 2). Respirometric index achieved values compatible with indication of a stable $\mathrm{RI}_{4}<5 \mathrm{mg} \mathrm{O}_{2} / \mathrm{g}$ TS (Barrena Gómez et al., 2006).

Moreover, results obtained for the heaps containing bioplastics (BioPOF) displayed no substantial differences compared to blank heaps (OF); therefore, in the context of composting, bioplastics do not seem to impact on final compost quality. Negligible alteration in the matrix due to bioplastics was observed by previous authors, both in compost (Balaguer et al., 2016) and in soil (Adhikari et al., 2016).

\subsection{Granulometry of bioplastics}

The fragmentation process was clearly visible in the tested material, mainly during the thermophilic phase of composting. Figure 3 shows the granulometric curves of small and large bioplastics, with an average value between the two lines of each size (BioP small and BioP big).

A substantial reduction of the initial size was manifested during the thermophilic phase: the granulometry of the particles of both BioP small and BioP big moved towards $10 \mathrm{~mm}$. This trend of high fragmentation was expected in view of the typically higher intensity of the first phase of composting (Insam and de Bertoldi, 2007), (Tiquia et al., 2002).

At the end of the process, the granulometric curves of bioplastics revealed that the percentage of pieces passing through $5 \mathrm{~mm}$ sieve reached $55 \%$ and $20 \%$ in BioP small and BioP big respectively. Moreover, the curves outlined the generation of micro-pieces below the $2 \mathrm{~mm}$ regulatory threshold.

Figure 4 reports the average trend in size reduction of bioplastics based on data obtained from the granulometric curves. After a strong size reduction found in the end of the thermophilic phase, a linear trend was defined both for
BioP small and BioP big during the mesophilic phase. The bullet points on the graphs are calculated in accordance with Equation 1. The graph illustrates the equations for the trend of each line.

The steep slope observed during the thermophilic phase confirmed the high efficiency of this phase in achieving fragmentation (Balaguer et al., 2016). The second, lower slope indicated a slowing down of the fragmentation process during the curing phase. The different size of bioplastics at the beginning of the experiment clearly affected the fragmentation process during the thermophilic phase; however, during the last part of the process the BioP small and BioP big curves definitely tended to converge.

The hypothetic time required to achieve an average final size of 5 and $2 \mathrm{~mm}$ was extrapolated using linear equations obtained for the curing phase, corresponding to 80 and 100 days of composting, respectively.

\subsection{Bioplastics mass}

During the composting process, bioplastic mass decreased to $20-30 \%$ of the initial mass, corresponding approximately to the mass achieved by the compostable heaps, as previously discussed. Final results were achieved on inclusion of variables relating to water and surface dirt. In particular, alteration (increase) of mass due to surface dirt was lower at days 10 and 25 than at days 40 and $55^{\text {th }}$, yielding percentages of $10-20 \%$ and $20-30 \%$, respectively. Mass trend is reported in Table 3, illustrating average values obtained from the two lines for BioP small and big. It is evident how mass was still stable after the thermophilic phase, while during the curing phase it underwent a substantial decrease, showing a similar behaviour for both BioP. Mass decrease may be taken as an index of biodegradation, occurring thanks to the activity of microorganisms in the curing phase (Chiumenti et al., 2005) (Insam and de Bertoldi, 2007), (Tiquia et al., 2002).

\subsection{Degradation of bioplastics investigated by means of FTIR analysis}

Results obtained at FTIR-ATR analysis confirmed that the degradation of bioplastics occurred mainly during the

TABLE 2: C/N ratio and respirometric index RI4 parameters during composting.

\begin{tabular}{|c|c|c|c|c|c|c|c|c|c|c|}
\hline & \multicolumn{5}{|c|}{$\mathrm{C} / \mathrm{N}\left(\mathrm{mgO}_{2} / \mathrm{gTS}\right)$} & \multicolumn{5}{|c|}{$\mathrm{RI}_{4}$} \\
\hline & \multicolumn{10}{|c|}{ Line 1} \\
\hline & $1^{\text {st }}$ & $10^{\text {th }}$ & $25^{\text {th }}$ & $40^{\text {th }}$ & $55^{\text {th }}$ & $1^{\text {st }}$ & $10^{\text {th }}$ & $25^{\text {th }}$ & $40^{\text {th }}$ & $55^{\text {th }}$ \\
\hline OF & 29 & 21 & 13 & 17 & 13 & 52.3 & 38.7 & 38.2 & 26.4 & 1.3 \\
\hline BioPOF small & 25 & 19 & 17 & 22 & 12 & 51.9 & 39.1 & 41.0 & 33.3 & 3.4 \\
\hline BioPOF big & 24 & 19 & 16 & 18 & 12 & 49.8 & 36.5 & 43.7 & 30.2 & 5.3 \\
\hline \multirow[t]{3}{*}{ Average } & 26 & 19 & 15 & 19 & 13 & 51.3 & 38.1 & 41.0 & 30.0 & 3.4 \\
\hline & \multicolumn{10}{|c|}{ Line 2} \\
\hline & $1^{\text {st }}$ & $10^{\text {th }}$ & $25^{\text {th }}$ & $40^{\text {th }}$ & $55^{\text {th }}$ & $1^{\text {st }}$ & $10^{\text {th }}$ & $25^{\text {th }}$ & $40^{\text {th }}$ & $55^{\text {th }}$ \\
\hline OF & 25 & 19 & 18 & 17 & 13 & 49.5 & 33.9 & 27.1 & 13.1 & 8.6 \\
\hline BioPOF small & 23 & 17 & 14 & 14 & 11 & 50.0 & 34.8 & 35.4 & 22.1 & 6.6 \\
\hline BioPOF big & 32 & 18 & 14 & 14 & 12 & 53.2 & 27.9 & 32.1 & 16.2 & 8.4 \\
\hline Average & 26.8 & 18.0 & 15.6 & 14.8 & 12 & 50.9 & 32.2 & 31.5 & 17.1 & 7.9 \\
\hline
\end{tabular}



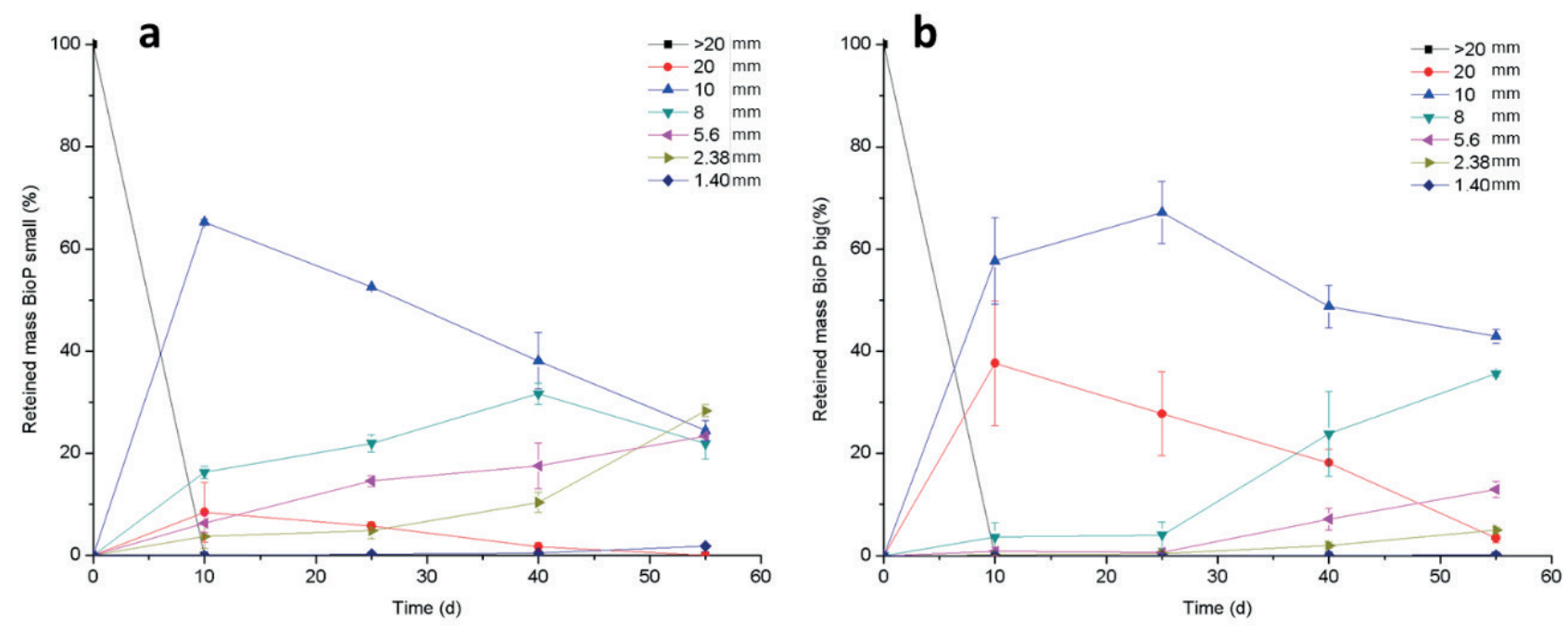

FIGURE 3: Bioplastics granulometric curves during composting process for bioplastics small (BioP small) (a) and big (BioP big) (b).

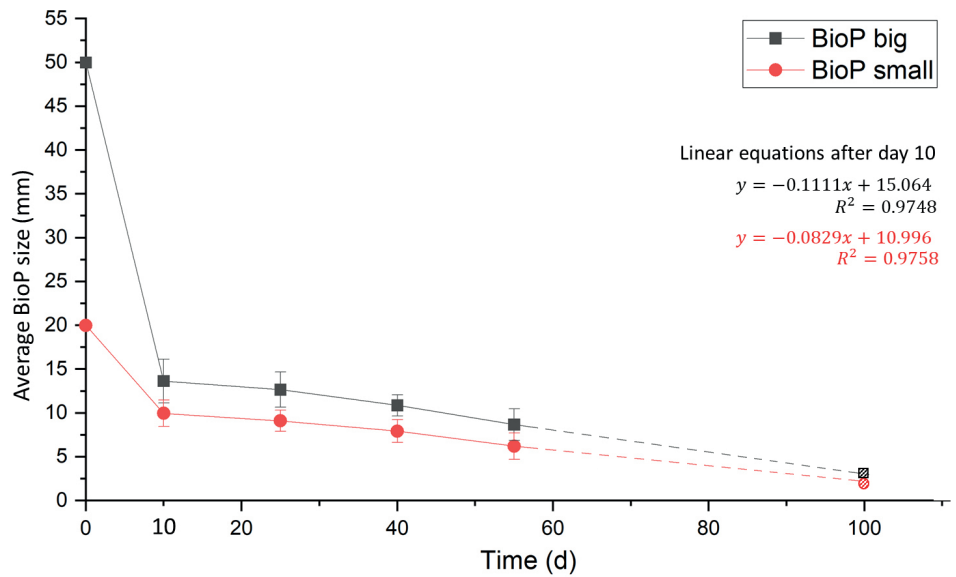

FIGURE 4: Evolution over time of size reduction (average) of bioplastics due to disintegration and biodegradation.

curing phase. In Figure 5, the spectrum of one sample (chosen from hundreds with similar results) for each day of analysis is reported.

After ten days of composting, the spectrum was almost identical to the initial spectrum, and at the end of the thermophilic phase few differences were noticeable; the most substantial changes, however occurred during the curing phase.

Prior to the $25^{\text {th }}$ day, the spectra displayed a peak at $1717 \mathrm{~cm}^{-1}$ corresponding to the initial $\mathrm{C}=0$ group present in the structure of the tested bioplastic polymers: the peak

TABLE 3: Bioplastic (BioP) mass decrease during composting.

\begin{tabular}{l|ccc} 
& \multicolumn{2}{c}{ BioP mass (\%) } \\
\hline Time (d) & BioP small & BioP big \\
\hline $1^{\text {tt }}$ & 100 & 100 \\
\hdashline $10^{\text {th }}$ & 96.8 & 95.8 \\
\hline $25^{\text {th }}$ & 60.0 & 79.0 \\
\hdashline $40^{\text {th }}$ & 45.8 & 40.0 \\
\hline $55^{\text {th }}$ & 29.8 & 18.3 \\
\hline
\end{tabular}

is strictly relatable to PBAT present in the polymer (Elfehri Borchani et al., 2015). . Indeed, the disappearance of the peak in the spectra of day 40 and 55 can be considered as an index of at least a partial degradation of PBAT in the polymer. However, it is fair to highlight the trend of peak 727 $\mathrm{cm}^{-1}$, which previous authors identified as representative of bonds typical of PBAT (Weng et al., 2013). Even after 55 days of composting, the peak is still present in the spectrum, assessing that this part of the polymer has not yet been degraded. Importantly, the two peaks in the surrounding of $1270 \mathrm{~cm}^{-1}$ are the main peaks relatable to starch in the polymer; their substantial decrease is a clear index of starch degradation in composting (Elfehri Borchani et al., 2015) (Ruggero et al., 2020).

Shortly after the $25^{\text {th }}$ day, and particularly on days 40 and 55 , an increase in concentration of the peaks in the regions between 1650 and $1600 \mathrm{~cm}^{-1}$, and between 1450 and $1400 \mathrm{~cm}^{-1}$ was observed. These new peaks may be attributed to the formation of carboxylate ions (R-COO-) by microorganisms and amidic groups of proteinaceous materials, respectively, in line with the findings of previous studies (Ruggero et al., 2020) (Arrieta et al., 2014). Moreover, an 


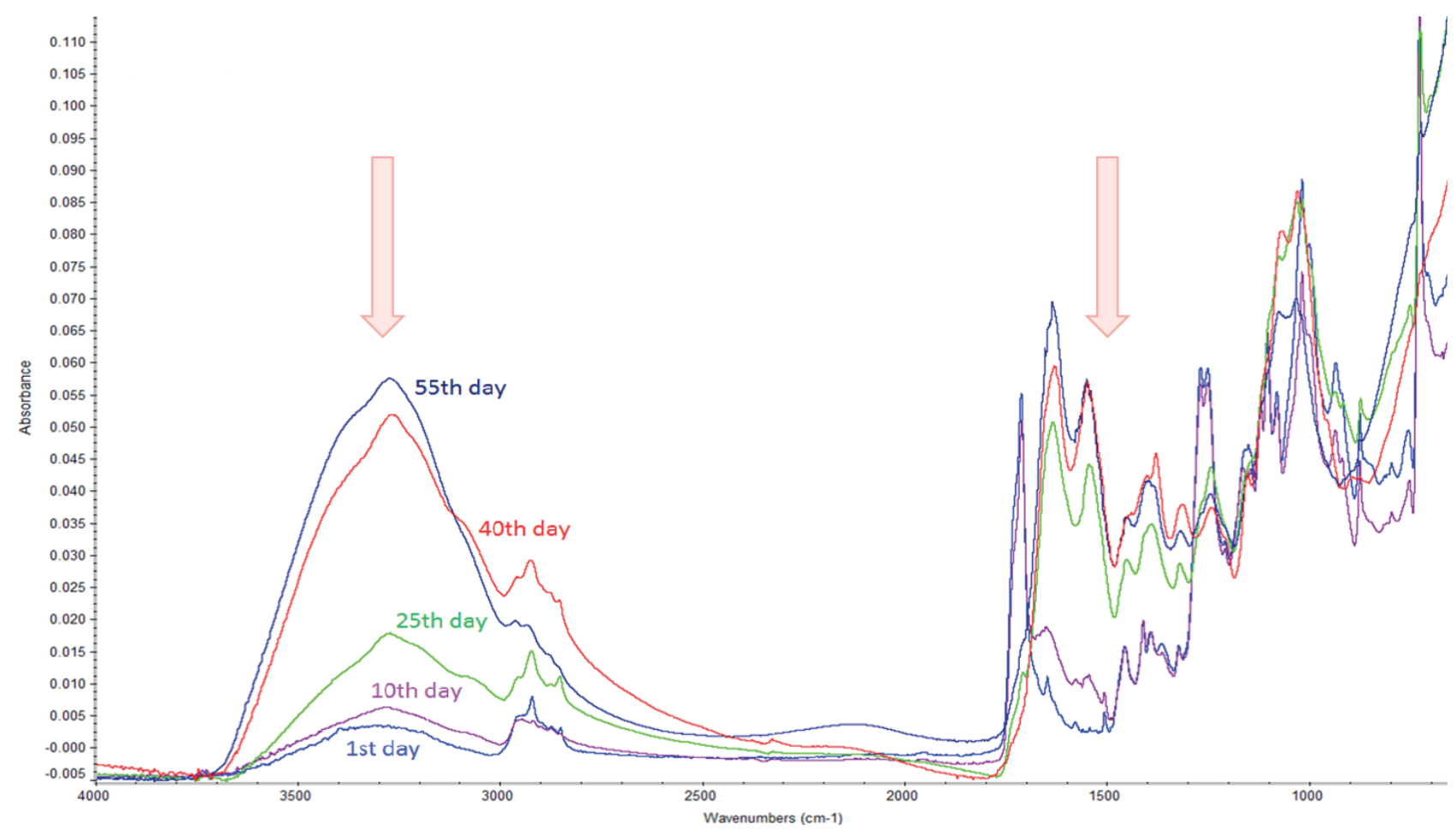

FIGURE 5: Spectra from the same heap at different times of the composting process.

increase of $3270 \mathrm{~cm}^{-1}$ peak concentration is imputable to the $-\mathrm{OH}$ group, a further sign of hydrolytic degradation of the material.

\subsection{Visual analysis}

Visual analysis of bioplastics during the process revealed increasing amounts of surface dirt on the pieces produced by contact with organic waste, in addition to limited signs of bacterial activity in terms of lateral erosion. With regard to the smallest bioplastic particles, a marked similarity with compost was detected mainly in the curing phase.

During manual operations carried out in the sieving analysis, it was visually noted that due to softening and increasing humidity, the bioplastics tended to wrap the food waste, thus preventing full degradation of the food waste.

Evolution of the visual aspect of bioplastics was photographically documented during the tests, as shown in Figure 6.

\section{CONCLUSIONS}

The present study highlighted a series of important observations: (i) based on the parameters monitored, the composting of heaps ended after a period of 55 days; however, at the end of this period, the degradation of bioplastics failed to meet the regulatory requirements for compostability ( $\leq 10 \%$ sized $>2 \mathrm{~mm}$ ). (ii) changes in the physico-chemical features of bioplastics suggested that biodegradation had mainly occurred during the curing phase, as a result of the activity of microorganisms, while (iii) the granulometric trend of size reduction demonstrates that fragmentation is markedly enhanced during the thermophilic phase. Accordingly, the initial dimensions of the bioplastics were found to impact on the fragmentation process. Moreover, two linear trends were identifiable in the size reduction curve: a steep slope in the thermophilic phase, which evolved into a much slower trend of fragmentation during the curing phase. Extrapolation of experimental data has revealed the need for a 100-day period of composting in order to meet standard requirements for the compostability of bioplastics.

Taking into account the future extended use of bioplastics and marketing of new products, including cutlery, food packaging and coffee capsules, further research should be undertaken. Indeed, further research should extend the experimental day up to more than 100 days and be based on the inclusion of a series of additional features of bioplastic and variables with an aim to providing an in-depth analysis of the conditions (composting time, temperature, initial quantity and size) best suited to promoting degradation in composting.

\section{REFERENCES}

Accinelli, C., Saccà, M.L., Mencarelli, M., Vicari, A., 2012. Deterioration of bioplastic carrier bags in the environment and assessment of a new recycling alternative. Chemosphere 89, 136-143. https://doi. org/10.1016/j.chemosphere.2012.05.028

Adhikari, D., Mukai, M., Kubota, K., Kai, T., Kaneko, N., Araki, K.S., Kubo, M., 2016. Degradation of Bioplastics in Soil and Their Degradation Effects on Environmental Microorganisms. J. Agric. Chem. Environ. 05, 23-34. https://doi.org/10.4236/jacen.2016.51003

Arrieta, M.P., López, J., Rayón, E., Jiménez, A., 2014. Disintegrability under composting conditions of plasticized PLA-PHB blends. Polym. Degrad. Stab. 108, 307-318. https://doi.org/10.1016/j. polymdegradstab.2014.01.034

Assobioplastiche, 2018. http://www.assobioplastiche.org. 

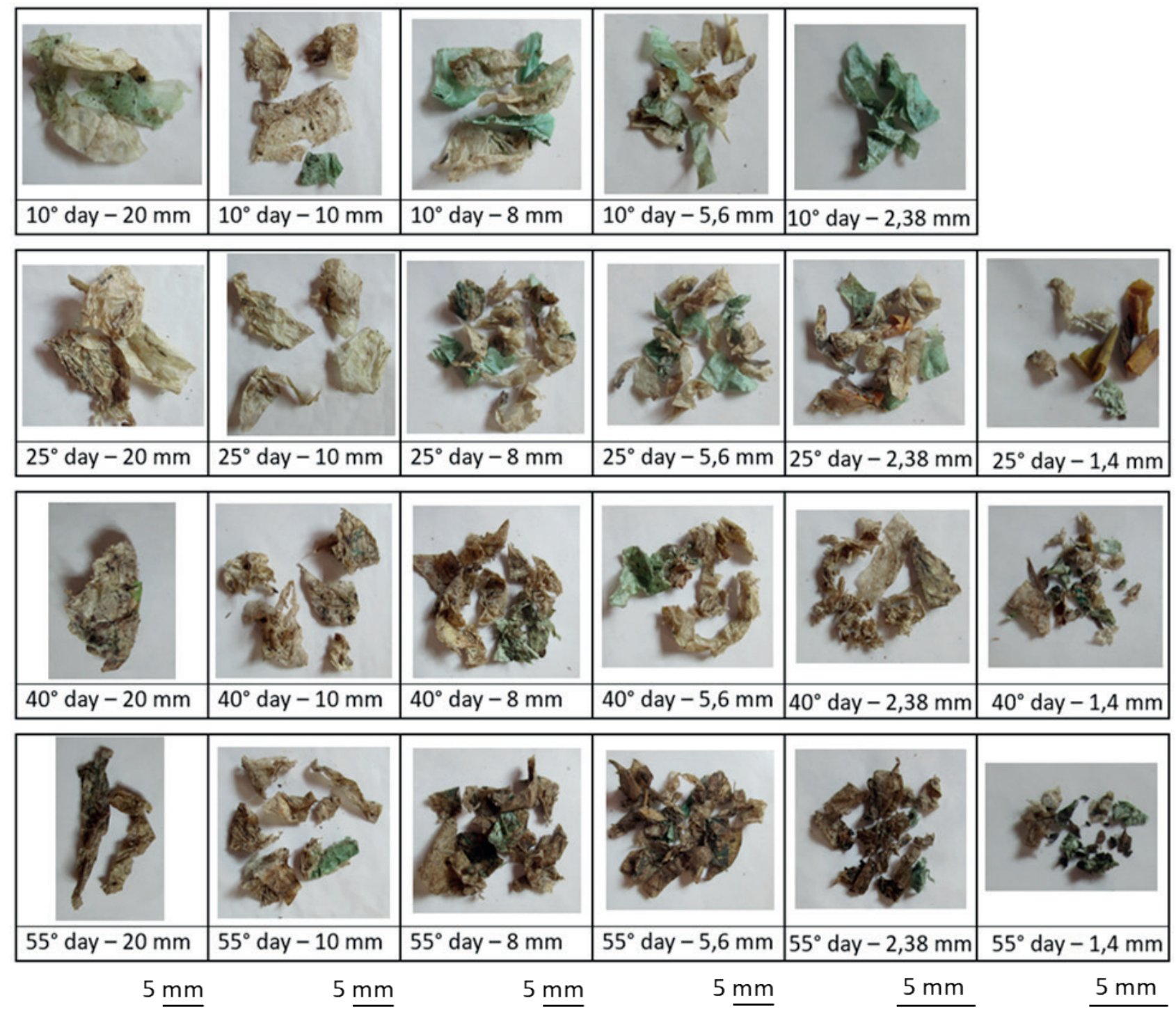

FIGURE 6: Photographs of bioplastic samples showing size reduction and variation over time.

Balaguer, M.P., Aliaga, C., Fito, C., Hortal, M., 2016. Compostability assessment of nano-reinforced poly(lactic acid) films. Waste Manag. 48, 143-155. https://doi.org/10.1016/j.wasman.2015.10.030

Barrena Gómez, R., Vázquez Lima, F., Sánchez Ferrer, A., 2006. The use of respiration indices in the composting process: A review. Waste Manag. Res. 24, 37-47. https://doi.org/10.1177/0734242X06062385

Bioplastics European, 2019. www.european-bioplastics.org.

Byun, Y., Kim, Y.T., 2013. Bioplastics for Food Packaging: Chemistry and Physics, Innovations in Food Packaging: Second Edition. Elsevier Ltd. https://doi.org/10.1016/B978-0-12-394601-0.00014-X

Chiumenti A., Chiumenti R., Diaz L.F., Savage G.M., Eggerth L.L., Goldstein N. (2005) Modern Composting Technologies. BioCycle-JG Press, Emmaus, PA, USA. ISBN 0932424295, 9780932424297

Elfehri Borchani, K., Carrot, C., Jaziri, M., 2015. Biocomposites of Alfa fibers dispersed in the Mater-Biß type bioplastic: Morphology, mechanical and thermal properties. Compos. Part A Appl. Sci. Manuf. 78, 371-379. https://doi.org/10.1016/j.compositesa.2015.08.023

Emadian, S.M., Onay, T.T., Demirel, B., 2017. Biodegradation of bioplastics in natural environments. Waste Manag. 59, 526-536. https:// doi.org/10.1016/j.wasman.2016.10.006

EN 13432, 2000. Packaging - Requirements for packaging recoverable through composting and biodegradation - Test scheme and evaluation criteria for the final acceptance of packaging.

EN 14045, 2003. Packaging - Evaluation of the disintegration of packaging materials in practical oriented tests under defined composting conditions.
Gómez, E.F., Michel, F.C., 2013. Biodegradability of conventional and bio-based plastics and natural fiber composites during composting, anaerobic digestion and long-term soil incubation. Polym. Degrad. Stab. 98, 2583-2591. https://doi.org/10.1016/j.polymdegradstab.2013.09.018

Hahladakis, J.N., lacovidou, E., 2018. Closing the loop on plastic packaging materials: What is quality and how does it affect their circularity? Sci. Total Environ. 630, 1394-1400. https://doi. org/10.1016/j.scitotenv.2018.02.330

Hahladakis, J.N., Velis, C.A., Weber, R., lacovidou, E., Purnell, P., 2018. An overview of chemical additives present in plastics: Migration, release, fate and environmental impact during their use, disposal and recycling. J. Hazard. Mater. 344, 179-199. https://doi. org/10.1016/j.jhazmat.2017.10.014

Insam, H., de Bertoldi, M., 2007. Chapter 3 Microbiology of the composting process, Compost science and technology. https://doi. org/10.1016/S1478-7482(07)80006-6

Iovino, R., Zullo, R., Rao, M.A., Cassar, L., Gianfreda, L., 2008. Biodegradation of poly(lactic acid)/starch/coir biocomposites under controlled composting conditions. Polym. Degrad. Stab. 93, 147-157. https://doi.org/10.1016/j.polymdegradstab.2007.10.011

ISPRA, 2019. Rapporto Rifiuti Urbani 2019.

ISPRA, 2017. Rapporto rifiuti urbani 2017. ISBN: 978-88-448-0852-5. https://doi.org/.1037//0033-2909.126.1.78 
Javierre, C., Sarasa, J., Claveria, I., Fernandez, A., 2015. Study of the Biodisintegration on a Painted Bioplastic. Mater. Waste.

Karana, E., 2012. Characterization of "natural" and "high-quality" materials to improve perception of bio-plastics. J. Clean. Prod. 37, 316-325. https://doi.org/10.1016/j.jclepro.2012.07.034

Massardier-Nageotte, V., Pestre, C., Cruard-Pradet, T., Bayard, R., 2006. Aerobic and anaerobic biodegradability of polymer films and physico-chemical characterization. Polym. Degrad. Stab. 91, 620-627. https://doi.org/10.1016/j.polymdegradstab.2005.02.029

Mohee, R., Unmar, G.D., Mudhoo, A., Khadoo, P., 2008. Biodegradability of biodegradable/degradable plastic materials under aerobic and anaerobic conditions. Waste Manag. 28, 1624-1629. https://doi. org/10.1016/j.wasman.2007.07.003

Package., F.C.E., 2018. EU-European Union, 2018. https://ec.europa. eu/environment/circular-economy/index_en.htm (last access 5 August 2019).

Peelman, N., Ragaert, P., De Meulenaer, B., Adons, D., Peeters, R., Cardon, L., Van Impe, F., Devlieghere, F., 2013. Application of bioplastics for food packaging. Trends Food Sci. Technol. 32, 128-141. https://doi.org/10.1016/j.tifs.2013.06.003

Region, A.-E.A. of V., 2015. II recupero della frazione organica in Veneto.
Ruggero, F., Carretti, E., Gori, R., Lotti, T., Lubello, C., 2020. Monitoring of degradation of starch-based biopolymer fi Im under different composting conditions, using TGA, FTIR and SEM analysis. Chemosphere 246, 125770. https://doi.org/10.1016/j. chemosphere.2019.125770

Ruggero, F., Gori, R., Lubello, C., 2019. Methodologies to assess biodegradation of bioplastics during aerobic composting and anaerobic digestion : A review. https://doi.org/10.1177/0734242X19854127

Shruti, V.C., Kutralam-Muniasamy, G., 2019. Bioplastics: Missing link in the era of Microplastics. Sci. Total Environ. 697, 134139. https:// doi.org/10.1016/j.scitotenv.2019.134139

Tiquia, S.M., Richard, T.L., Honeyman, M.S., 2002. Carbon, nutrient, and mass loss during composting. Nutr. Cycl. Agroecosystems 62, 15-24. https://doi.org/10.1023/A:1015137922816

Weng, Y., Jin, Y., Meng, Q., Wang, L., Zhang, M., Wang, Y., 2013. Biodegradation behavior of poly (butylene adipate-co- terephthalate) (PBAT), poly (lactic acid)(PLA), and their blend under soi conditions. Polym. Test. 32, 918-926. https://doi.org/10.1016/j. polymertesting.2013.05.001

Yates, M.R., Barlow, C.Y., 2013. Life cycle assessments of biodegradable commercial biopolymers - A critical review. Resour. Conserv. Recycl. 78, 54-66. https://doi.org/10.1016/j.resconrec.2013.06.010 